\title{
Co-Teaching: A Simple Solution That Isn't Simple After All
}

\author{
Marilyn Friend \\ University of North Carolina at Greensboro
}

\begin{abstract}
Among the many options that professional educators are developing to better help their increasingly diverse students reach their potential, co-teaching is emerging as an innovative and potentially effective approach. Co-teaching occurs when two professionals, typically a general education teacher and a special education teacher, partner in delivering instruction. It is a way to ensure that students with disabilities or other special needs have access to the same curriculum and opportunities to succeed in the general education setting. Although the research base on coteaching is still emerging, it suggests that co-teaching is far more complex to implement effectively than it might seem at first consideration. Challenges to co-teaching that have been identified and must be addressed include: arranging time for co-planning, building positive working relationships between co-teaching partners, clarifying roles and responsibilities, and ensuring administrative support. When creative strategies for arranging common planning time, building understanding and collaboration between co-teachers, planning and delivering instruction, and enlisting principal and other administrative supports are implemented, the potential for co-teaching to improve student outcomes is significant.
\end{abstract}

As the students who attend U.S. public schools become more diverse, so should the strategies for facilitating student achievement. In recent years, efforts to improve student outcomes have focused on reading instruction (e.g., Kamps et al., 2008), math instruction (e.g., Ketterlin-Geller, Chard, \& Fien, 2008), and behavior supports (e.g., Lane, Wehby, \& Robertson, 2007). Schools are implementing comprehensive systems so that struggling students' learning and behavior problems are addressed as soon as they are apparent, using data-based interventions that are closely monitored for effectiveness (e.g., Hoover \& Patton, 2008). One service delivery option with the potential to serve as a vehicle for implementing the reading, math, behavior, and other interventions that improve student learning is co-teaching (Coltrane, 2002; Friend \& Cook, 2007).

Co-teaching occurs when a general education teacher and a specialist-often a special education teacher, reading specialist, speech/language therapist, or bilingual teacher-work as partners to teach a diverse group of students. Co-teaching presumes that both educators actively participate in the delivery of instruction, share responsibility for all their students, assume accountability for student learning, and acquire instructional resources and space. In co-teaching, the exact contribution that each person makes may vary, but together the educators create a learning situation that cannot be produced by a solo teacher. In elementary schools, co-teaching often occurs during reading and math instruction so that flexible grouping and individualized instruction become a reality. In middle and high schools, co-teaching may occur in any subject area or course in which diverse learners are enrolled (Friend, 2008). 
Reasons for the growing popularity of co-teaching in today's schools are easily identified. First, the provisions of the No Child Left Behind Act (NCLB, 2001), including the requirement that nearly all students reach a high standard of academic achievement and that they are taught by highly qualified teachers, has prompted focus on this service delivery option as a means for addressing legislative mandates. That is, by placing students with disabilities or other special needs in general education classrooms and transferring their special education services to that location through co-teaching, they are ensured access to a highly qualified teacher in the content area, a qualification that remedial specialists, especially special educators, may not possess. Second, additional momentum for the popularity of co-teaching was provided by the most recent reauthorization of the Individuals with Disabilities Education Improvement Act (IDEA) in 2004. This law clarified that NCLB provisions apply to students with disabilities as well as students without disabilities. Specifically, it reemphasized a student's right to access the same curriculum as peers without disabilities and to do so in the general education setting, unless evidence clearly indicates that the setting is not appropriate. In other words, co-teaching offers an approach for ensuring curriculum access and doing so in the legislatively required least restrictive environment (LRE). Combined, these federal laws provide an impetus that has moved co-teaching from an interesting and encouraged means of providing services based on a philosophy about educating students with disabilities in general education because "it is the right thing to do," to a widely implemented approach that has become a focus for inquiry and analysis.

Given the increasing popularity of co-teaching and implied legislative stimulus for it, educators should not only be aware of co-teaching, but also enhance their knowledge regarding this practice. This article provides a brief overview of the central characteristics of co-teaching and an analysis of several challenges that co-teachers encounter. The goal of the article is to ensure that educators who are implementing coteaching for the first time recognize both its potential and pitfalls and that those who are engaged in co-teaching reflect on their practices and programs as well as how to improve them. Additionally, it clarifies that while co-teaching seems at first glance to be a relatively simple strategy for reaching diverse learners, in reality it is a sophisticated service option requiring a strong professional commitment and systemic supports.

\section{Understanding Co-Teaching: An Emerging Research Base}

Especially when employed as a means of providing special education services, co-teaching is an intuitively attractive method for accomplishing the expectations established by current legislation because it provides an opportunity to blend the somewhat different areas of expertise of professionals (Friend, 2008). General education teachers should contribute these four primary areas of expertise: (a) an indepth knowledge of the curriculum and how it should be taught, (b) the ability to manage a large group of students through the various activities that occur in their classes (classroom management), (c) an understanding of typical learning and behavior patterns of students, and (d) a focus on the pacing of instruction so that the rigor expected can be accomplished. Special educators also should offer four primary areas of expertise: (a) an in-depth knowledge and skills for the process of learning as exemplified by their ability to provide accommodations, modifications, strategies, 
remediation, and tools to facilitate student learning; (b) an understanding of each student's individual needs including those related to learning, behavior, family, and other areas; (c) the ability to attend to required paperwork including individualized education programs (IEPs); and (d) a focus on mastery learning. It is not so much that the educators' knowledge and skills are completely different; rather, the two sets of knowledge and skills form a sort of Venn diagram in which there are overlapping similarities and distinct differences. These differences are the strength of this service delivery approach. They illustrate how co-teaching mirrors contemporary trends in business and other professions of uniting diverse individuals who together can create ideas and products that no single individual could have imagined (e.g., Reiter-Palmon \& Illies, 2004). That is, co-teaching suggests that professionals who share instruction can combine their knowledge and skills to create learning environments in which instruction is both rigorous and flexible, standards-based but accommodated to each student's unique learning needs. They can do so in a way that respectfully draws on each individual's talents, acknowledging that it is unlikely that any single professional in today's schools could possibly know everything necessary to optimize learning.

Although logic suggests that co-teaching should result in a sophisticated teaching and learning environment in which diverse student needs can readily be met, the emerging picture of co-teaching is far more complex than the implied idyllic classroom practice. For example, in a review of 32 qualitative studies of co-teaching, Scruggs, Mastropieri, and McDuffie (2007) found that general and special educators reported positive perceptions of co-teaching, but they noted the need for a wide variety of supports in order for the service to be effective. These authors also found that special educators were more likely to serve primarily in roles that approximate those of teaching assistants or paraprofessionals, rather than roles of collegial peers. In another analysis of this means for educating diverse student groups, Magiera and Zigmond (2005) reported that middle school students with disabilities in co-taught classes received less attention than they did when they participated in general education classes that were taught by the general education teacher alone. In yet another study, Keefe and Moore (2004) interviewed high school teachers regarding co-teaching. They found that high school educators stressed the importance of compatibility between teaching partners, the importance of special educators having knowledge of content at a level to foster their active participation in teaching, and the potential of co-teaching in raising student achievement as long as it was not utilized as a panacea for all student learning needs.

The research base on academic and related outcomes for students with disabilities in co-taught classes is another indication that this instructional arrangement is fraught with challenges. Some studies indicate positive outcomes in terms of student academic achievement and behavior (e.g., Idol, 2006). However, many studies of coteaching (e.g., Murray, 2004; Walther-Thomas, 1997) have primarily gathered data about teacher, administrator, parent, and/or student perceptions of co-teaching. Those that have examined student outcomes indicate equivocal results (e.g., Mastropieri et al., 2005), often depending on the working relationship between the teachers.

What is clear from the studies just summarized as well as the additional research and conceptually-based literature regarding co-teaching (e.g., Davidson, 2006; Dieker \& 
Murawski, 2003; Friend, 2007) is that this seemingly straightforward way to provide educational opportunities to students with disabilities and other special needs requires careful attention to preparation and implementation. Too often, issues arise and must be addressed if the potential of co-teaching is to be realized.

\section{The Challenges of Co-Teaching and Possible Solutions}

In examining studies of co-teaching and the views of educators in the field, it is clear that several key issues affect co-teaching, both at the classroom and programmatic levels. These issues include logistics, especially common planning time; the working relationship between co-teaching partners; roles and responsibilities in the classroom; and administrative support. Although no easy solutions are likely to be found, a constructive approach to addressing these dilemmas can foster co-teaching success.

\section{Co-Planning Time}

Whether co-teaching is implemented in elementary schools, middle schools, or high schools and whether those schools are in urban, suburban, or rural communities and well-funded or under-funded, professionals universally find that co-teachers do not have adequate planning time, and this affects the quality of their practice. In fact, the problem of common planning time is the dilemma most frequently mentioned by all coteachers as constraining their practice (Ashton, 2003). When asked how much planning time should be allocated, co-teachers usually express a preference for a minimum of a weekly co-planning period for each partnership. For example, if a special educator works with three general educators, that teacher would be assigned to a co-planning period with each of those teachers each week. It is ideal if this planning time can be arranged. In a few schools, this situation occurs through grade level or team planning options, by a strategic arrangement of related arts in elementary schools, or through coordinated assigned planning periods in middle and high schools. However, given current pressure to raise student achievement and the resulting and understandable reluctance on the part of administrators to release teachers each week from a teaching responsibility when ideal scheduling arrangements are not possible, this amount of planning time, especially across multiple teachers, is unlikely to be possible.

Planning time options. Not surprisingly, the need for planning time is not unique to co-teachers (Johnston, Knight, \& Miller, 2007). However, it is essential for coteachers, especially when their relationships are new. In many cases a realistic option is to consider planning as a two-component process. The first component involves sharing key decisions and discussing the most critical topics, a type of planning that occurs periodically, but at least once per month, for a class period, an hour, or whatever planning time can be made available. The companion to this planning is the second component which includes the on-the-fly conversations that occur on a daily or asneeded basis. If the former type of planning is supported, the latter type can supplement it and result in co-teaching success. 
These are examples of strategies for arranging periodic planning time:

Compensated summer planning. If professionals can receive a stipend for planning just prior to the beginning of the school year, they can set up their co-taught class, discuss introductions and beginning activities, and overview instruction that occurs during the first month of the school year.

Planning with assigned continuing education credit. In some districts, teachers request and obtain credit for co-teaching planning that they complete in sessions held after school. Especially when several sets of co-teaching partners come together for such planning, this option constitutes an intense, immediately useful, reflective, and recommended type of staff development (e.g., Hargreaves, 2007). It provides teachers with compensated time, even though the time is outside school hours.

Planning on district staff development days. Co-teaching teams might be released from part of the planned activities during district staff development days for the purpose of shared planning.

Notice that the co-planning options described share the intent of bringing coteachers together but do so with minimal loss of student instructional time. These periodic planning sessions are supplemented with the brief planning moments that for too many co-teachers currently constitute the only planning that occurs. That is, coteachers who have discussed upcoming units, chapters, novels, or objectives touch base by having brief discussions as students begin a class period or independent instructional activity, during passing periods, or as students transition from one activity to another. During these conversations, teachers quickly discuss lesson details, coteaching assignments, and student matters. When frequent common planning is not possible, this two-pronged approach can offer a realistic and effective alternative.

\section{Co-Teacher Working Relationships}

Co-teaching relationships are often likened to marital relationships in that they depend on commitment, negotiation, and flexibility. To be successful, co-teaching relies on two committed educators who care deeply about reaching their students and work diligently to achieve that goal. They problem solve to generate new strategies, resolve differences of opinion, and try alternative solutions if the original one is not successful. Co-teachers have a commitment to each other, as well, in terms of nurturing their professional relationship. Each educator works to bring out the best in the other person, and the result is improved outcomes for students and strong teaching partnerships.

Some co-teachers express concern, though, about their relationships with colleagues, especially when teaching partners are assigned by principals rather than educators volunteering to share instruction. A few teachers even refer to this as "arranged marriage." These sometimes reluctant participants note that co-teaching should occur when teachers choose to participate, that professionals should not be forced to do so. They reject the idea that co-teaching should be a standard of practice, expected of anyone who teaches. 
Making the choice to participate in co-teaching and selecting a partner is an understandable teacher preference since professionals generally believe they should not be told that this is a role responsibility. In some cases such choices are a viable option, but sometimes they are not possible. What if no one in a grade level or department volunteers to co-teach? If this means of providing student services is deemed appropriate, principals may need to assign co-teaching partnerships. Similarly, principals may decide that all teachers should work with the diversity of learners in a school, and then they may assign co-teaching to teachers who have not volunteered.

Strategies for fostering positive working relationships. The following ideas for nurturing strong, positive working relationships are helpful for all co-teaching partnerships, especially those that have been arranged:

1. Seek volunteers in new co-teaching programs. When co-teaching is new, it is often possible to find volunteers, which can create a positive foundation. Using volunteers provides willing participants the opportunity to experiment with co-teaching options, including the amount of time spent co-teaching and possibilities for logistics such as planning time. These early implementers can fine-tune the program before those who are less enthusiastic about co-teaching are asked to participate. The result can be a more overall positive view of co-teaching with co-teachers more committed to building strong professional relationships with their partners.

2. Give potential co-teachers choices. In established programs in large schools, principals can facilitate the assignment of co-teaching partners by asking all teachers who are interested in co-teaching to identify two or three individuals with whom they would be most comfortable working. No promises are made and the principal retains decision-making authority, but at least choices can be provided.

3. Make staff development meaningful. Meaningful staff development can help immensely in fostering working relationships. Although it may seem obvious, the first requirement is that co-teachers jointly participate in workshops, book studies, learning communities, and other staff development activities. Conversations about their expectations, teaching styles, understanding of students, and preferred classroom practices can lay the groundwork for a successful partnership.

4. Resolve small issues before they become big problems. Similar to differences encountered in marital relationships, small matters that are bothersome to coteachers should be addressed before they become more serious. Whether the topic concerns student discipline, teaching strategies, or neatness of a classroom, negotiating a compromise that is acceptable to both partners is much easier if accomplished before either person is annoyed or frustrated.

In many ways, co-teaching exemplifies the increasing importance of collaboration in public schools (Barth, 2006). The successful working relationships of co-teachers illustrate how pooling strengths can have great benefits for students and how the stress of teaching can be more manageable for teachers. 


\section{Classroom Roles and Responsibilities}

Although classroom roles and responsibilities are related to the working relationships between co-teachers, they extend beyond them. The question is this: Who assumes which instructional roles in a co-taught class? As noted earlier, considerable evidence suggests that general education teachers tend to take the lead role while special educators assist them instead of partnering in instructional delivery (e.g., Scruggs et al., 2007). The opposite situation may also occasionally occur in co-teaching in which either teacher may assist individual students. A core problem in co-teaching can result from the poor use of personnel. The underutilization of one teacher undermines the potential of co-teaching.

Solutions for assuring productive co-teaching roles and responsibilities. Ensuring that both teachers in a co-taught class have productive roles is primarily a matter of being deliberate about the practice. The following strategies facilitate the development of co-taught classes that are rich in instructional variety:

1. Use the six fundamental co-teaching approaches. Friend and Cook (2007) outlined six structures for co-teaching. They included some that are for occasional use, such as one person teaching while the other gathers data and one person teaching while the other provides individual assistance. However, other strategies are recommended for much more frequent use, including dividing students into three groups to rotate across instructional activities, two led by the teachers and one completed independently. A similar strategy calls for dividing students into two groups and each teacher leading instruction for his or her group, a strategy for review or discussion. The final two approaches involve working with a small group of students for remediation, enrichment, assessment, or another instructional purpose and teaming, an approach in which both teachers share the instruction of the large group.

2. Make effective use of co-planning. Using the six co-teaching approaches requires discussion during planning. Co-teachers might decide to use just three or four of the approaches during an upcoming unit of instruction. By discussing what they plan to do, they can ensure that both teachers have teaching responsibilities. If the special educator is not an expert in the academic content being addressed, as may happen in some high school classes, these approaches can be used to ensure that the teacher is prepared for specific instructional activities.

3. Debrief related to roles and responsibilities. Generally, co-teachers want to succeed. However, in the frenetic pace of the school day, they may fail to make time to take stock of their practices so that they can refine them. It is essential that co-teachers ask one another about roles in the classroom and continuously improve their shared instruction so that both educators are active participants. Doing so fosters exemplary practices.

By beginning with the expectation that the "co" in co-teaching truly means that both teachers should deliver instruction, co-teachers can become creative in how they 
go about their work. They should blend the approaches, create variations of them, and ultimately, reach the needs of their diverse students.

\section{Administrative Support}

All of the challenges of co-teaching discussed thus far relate to administrative support. More than 15 years ago, a co-teaching participant made this comment: "If your principal only knows one paragraph of information about co-teaching, it's going nowhere." This statement still holds considerable truth. Principals help teachers, other staff members, parents, and students prepare for co-teaching, and they arrange planning time and other logistics to make co-teaching feasible. They monitor the effectiveness of co-teaching to ensure that it is having the desired impact on student learning, and they engage teachers in problem solving when dilemmas arise.

Co-teachers sometimes lament that their principal supports co-teaching with words but not actions. They note that some administrators do not seem to understand the complexity of creating and sustaining co-teaching programs and leave too many of the details to the teachers. They believe that principals are the individuals who have the power to put into place the conditions that are necessary for co-teaching to have a positive impact on student learning (Scruggs et al., 2007; Walther-Thomas, 1997).

Enlisting administrative support. Principals have difficult jobs and co-teaching is just one of numerous issues that command attention. It is not particularly surprising that some (but not all) principals expect teachers to address the details of this service delivery option. However, enlisting meaningful principal support is crucial to the success of co-teaching. The following strategies may increase principal knowledge of and support for co-teaching:

1. Share selected pertinent information. Many principals have less information about co-teaching than teachers. They are better equipped to be supportive if teachers provide key information informing principals of their needs. For example, sharing articles or selected print materials from professional development activities can help educate principals about co-teaching.

2. Invite principals to professional development. If teachers invite principals to professional development activities about co-teaching, everyone learns together and the likelihood of success increases.

3. Propose solutions. Principals often want to support co-teachers, but they may not have specific solutions to the dilemmas being encountered. Co-teachers who propose solutions rather than simply listing problems are more likely to receive support. For example, when teachers provide principals with ideas for creating common planning time, solutions are far more likely to materialize than when teachers simply state that such time is needed.

4. Set expectations based on support. Without administrative support, co-teaching can exist, but it is likely to be limited in scope and subject to the preferences of individual teachers. If principal support is not in place, teachers should do the best that they 
can and then realize that their efforts may not be sufficient for long-term success. This does not mean teachers should abandon their efforts, but they should realize that systemic change requires administrative input so that they avoid frustration.

In nearly all cases, principals and other administrators want co-teaching to succeed. As its effectiveness is established, they often become stronger advocates. Coteachers can encourage principal support by conveying their successes, sharing academic achievement data, and constructively proposing alternatives for refining programs.

\section{Conclusion}

Co-teaching has tremendous potential as a strategy for improving the achievement of diverse learners. However, the emerging research base indicates that it is a far more complicated option than it may at first appear. Co-teaching partnerships require more than a casual agreement to work together in the classroom. For coteaching to be most effective, logistics must be addressed so that teachers' schedules permit co-planning, teachers' working relationships and classroom roles must be addressed, and administrative support must be in place. These potential challenges can, at times, seem daunting. However, the tremendous potential of co-teaching to enable students with disabilities and other special needs to access the same curriculum as their peers and achieve equally high standards makes the effort eminently worthwhile.

\section{References}

Ashton, T. M. (2003). What are teachers' greatest co-teaching concerns? Academic Exchange Quarterly, 7(3), 100-104.

Barth, R. S. (2006). Improving relationships within the schoolhouse. Educational Leadership, 53(6), 8-13.

Coltrane, B. (2002). Team teaching: Meeting the needs of English language learners through collaboration. Center for Applied Linguistics Newsletter, 25(2), 1-5. Retrieved April 2, 2008, from http://www.cal.org/resources/archive/news/2002spring/team.html.

Davidson, C. (2006). Collaboration between ESL and content teachers: How do we know when we are doing it right? International Journal of Bilingual Education and Bilingualism, 9, 454-475.

Dieker, L. A., \& Murawski, W. W. (2003). Co-teaching at the secondary level: Unique issues, current trends, and suggestions for success [Electronic version]. High School Journal, 86(4), 1-13.

Friend, M. (2007). The coteaching partnership. Educational Leadership, 64(5), 48-52. 
Friend, M. (2008). Co-teach! A manual for creating and sustaining effective classroom partnerships in inclusive schools. Greensboro, NC: Marilyn Friend, Inc.

Friend, M., \& Cook, L. (2007). Interactions: Collaboration skills for school professionals ( $5^{\text {th }}$ edition). Boston: Allyn and Bacon.

Hargreaves, A. (2007). Five flaws of staff development and the future beyond. Journal of Staff Development, 28(3), 37-38.

Hoover, J. J., \& Patton, J. R. (2008). The role of special educators in a multitiered instructional system. Intervention in School and Clinic, 43, 195-202.

Idol, L. (2006). Toward inclusion of special education students in general education: A program evaluation of eight schools. Remedial and Special Education, 27, 77-94.

Individuals with Disabilities Education Improvement Act, 20 U.S.C. $\S 1400$ et seq. (2004).

Johnston, J., Knight, M., \& Miller, L. (2007). Finding time for teams: Student achievement grows as district support boosts collaboration. Journal of Staff Development, 28(2), 14-18.

Kamps, D., Abbott, M., Greenwood, C., Wills, H., Veerkamp, M., \& Kaufman, J. (2008). Effects of small-group reading instruction and curriculum differences for students most at risk in kindergarten: Two-year results for secondary- and tertiary-level interventions. Journal of Learning Disabilities, 41, 101-114.

Keefe, E. B., \& Moore, V. (2004). The challenge of co-teaching in inclusive classrooms at the high school level: What the teachers told us. American Secondary Education, 32, 77-88.

Ketterlin-Geller, L. R., Chard, D. J., \& Fien, H. (2008). Making connections in mathematics: Conceptual mathematics intervention for low-performing students. Remedial and Special Education, 29, 33-45.

Lane, K. L., Wehby, J. H., \& Robertson, E. J. (2007). How do different types of high school students respond to schoolwide positive behavior support programs? Characteristics and responsiveness to teacher-identified students. Journal of Emotional and Behavioral Disorders, 15, 3-20.

Magiera, K., \& Zigmond, N. (2005). Co-teaching in middle school classrooms under routine conditions: Does the instructional experience differ for students with disabilities in co-taught and solo-taught classes? Learning Disabilities Research \& Practice, 20, 79-85.

Mastropieri, M. A., Scruggs, T. E., Graetz, J., Norland, J., Gardizi, W., \& McDuffie, K. (2005). Case studies in co-teaching in the content areas: Successes, failures, and challenges. Intervention in School and Clinic, 40, 260-270. 
Murray, C. (2004). Clarifying collaborative roles in urban high schools: General educators' perspectives. Teaching Exceptional Children, 36(5), 44-51.

No Child Left Behind Act, 20 U.S.C. § 6310 et seq. (2001).

Reiter-Palmon, R., \& Illies, J. J. (2004). Leadership and creativity: Understanding leadership from a creative problem-solving perspective. Leadership Quarterly, $15,55-77$.

Scruggs, T. E., Mastropieri, M. A., \& McDuffie, K. A. (2007). Co-teaching in inclusive classrooms: A metasynthesis of qualitative research. Exceptional Children, 73, 392-416.

Walther-Thomas, C. S. (1997). Co-teaching experiences: The benefits and problems that teachers and principals report over time. Journal of Learning Disabilities, 30 , 395-407.

doi:10.3776/joci.2008.v2n2p9-19

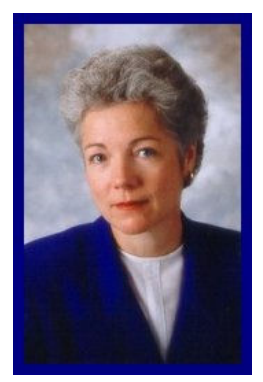

Marilyn Friend, Ph.D., has spent her career as a general education teacher, special education teacher, teacher educator, and staff developer. She is currently Professor of Education in the Department of Specialized Education Services at the University of North Carolina at Greensboro where she teaches coursework on inclusive practices and collaboration among service providers. She is also currently serving on the Board of the Teacher Education Division of the Council for Exceptional Children. She has consulted with school professionals nationally and internationally (more than 1000 presentations and projects in the United States, Canada, Europe, and Asia). She can be reached at m friend@uncg.edu. 